\title{
Clinical Evaluation of Recombinant Human Growth Hormone in Noonan Syndrome
}

\author{
MASAMICHI OGAWA ${ }^{1}$, NAOKI MORIYA ${ }^{2}$, HIROYUKI IKEDA², AYAKO TANAE ${ }^{3}$, TOSHIAKI TANAKA ${ }^{4}$, \\ KENJI OHYAMA ${ }^{5}$, OSAMU MORI ${ }^{6}$, TAKESHI YAZAWA ${ }^{7}$, KEINOSUKE FUJITA ${ }^{8}$, YOSHIKI SEINO ${ }^{9}$, \\ TOSHIHIDE KUBO ${ }^{9}$, HIROYUKI TANAKA ${ }^{9}$, YOSHIKAZU NISHI ${ }^{10}$ AND MASAAKI YOSHIMOTO ${ }^{11}$ \\ ${ }^{1}$ Department of Pediatrics, Nagoya University, School of Medicine, 65 Tsurumai-cho, Showa-ku, Nagoya 466-8550, Japan \\ ${ }^{2}$ Department of Pediatrics, Yamagata University School of Medicine, 2-2-2 Iida-nishi, Yamagata 990-9585, Japan \\ ${ }^{3}$ Division of Endocrinology and Metabolism, National Children's Hospital, 3-35-31 Taishido, Setagaya-ku, Tokyo 154-8567, Japan \\ ${ }^{4}$ Department of Endocrinology and Metabolism, National Children's Medical Research Center, 3-35-31 Taishido, Setagaya-ku, \\ Tokyo 154-8567, Japan \\ ${ }^{5}$ Department of Pediatrics, University of Yamanashi, 1110 Shimogato, Tamaho-cho, Nakakoma-gun, Yamanashi 409-3898, Japan \\ ${ }^{6}$ Department of Pediatrics, Meijo Hospital, 1-3-1 Sannomaru, Naka-ku, Nagoya 460-0001, Japan \\ ${ }^{7}$ Department of Pediatrics, Okazaki City Hospital, 3-1 Goshoai, Koryuji-cho, Okazaki, Aichi 444-8553, Japan \\ ${ }^{8}$ Pediatric Endocrinology, Department of Pediatrics, Osaka City General Hospital, 2-13-22 Miyakojima-hondori, Miyakojima-ku, \\ Osaka 534-0021, Japan \\ ${ }^{9}$ Department of Pediatrics, Okayama University Graduate School of Medicine and Dentistry, 2-5-1 Shikata-cho, Okayama $700-$ \\ 8558, Japan \\ ${ }^{10}$ Department of Pediatrics, Hiroshima Red Cross Atomic Bomb Hospital, 1-9-6 Senda-machi, Naka-ku, Hiroshima 730-8619, Japan \\ ${ }^{11}$ Department of Pediatrics, Nagasaki University School of Medicine, 1-12-4 Sakamoto, Nagasaki 852-8523, Japan
}

\begin{abstract}
The objective of this study was to investigate the effect of administration of recombinant human growth hormone $(\mathrm{hGH})$ in patients with Noonan syndrome. hGH was administered $(0.5 \mathrm{IU} / \mathrm{kg} /$ week $)$ to 15 patients with Noonan syndrome over a 2 year period. Average patient age prior to therapy was $7.5 \pm 2.5($ mean $\pm \mathrm{SD}$ ) yr, the height SD score was $-2.8 \pm 0.7$, and the pretreatment height velocity and bone age were $4.8 \pm 1.0 \mathrm{~cm} / \mathrm{yr}$ and $5.8 \pm 2.1 \mathrm{yr}$, respectively. The height velocity in the year prior to treatment, and 0-12 and 12-24 months after commencing treatment was $4.8 \pm 1.0 \mathrm{~cm} /$ $\mathrm{yr}, 7.0 \pm 1.2 \mathrm{~cm} / \mathrm{yr}$, and $5.5 \pm 0.6 \mathrm{~cm} / \mathrm{yr}$, respectively. The height velocity in the first year of treatment was significantly greater $(\mathrm{P}=0.0001, \mathrm{n}=14)$ than the pretreatment value, but there was no significant difference in the second year. The height SD scores at the commencement of treatment, and after 12 and 24 months of treatment were $-2.8 \pm 0.7,-2.4 \pm 0.7$, and $-2.2 \pm 0.5$, respectively. Bone age advanced by $1.1 \pm 0.5 \mathrm{yr}$ in the 12 months after commencing treatment. We conclude that the use of hGH may be beneficial in the treatment of Noonan syndrome, although further research is required.
\end{abstract}

Key words: Human growth hormone, Noonan syndrome, Bone age, Height velocity, Norditropin

(Endocrine Journal 51: 61-68, 2004)

HUMAN growth hormone (hGH) therapy is already approved in Japan for the indications of GH-deficient short stature, Turner syndrome and achondroplasia.

\section{Received: January 14, 2003}

Accepted: September 30, 2003

Correspondence to: Dr. Masamichi OGAWA, Ogawa Endocrine Clinic, NBN Izumi Bldg. 2F, 1-23-36, Izumi, Higashi-ku, Nagoya 461-0001, Japan
Recently, recombinant DNA technology has enabled the mass production of hGH, and research is flourishing into its use for growth promotion in diseases other than GH-deficient short stature.

While phenotypically resembling Turner syndrome, Noonan syndrome is characterized by a normal karyotype, and also affects males. Its frequency in the general population is estimated to be 1 in 1,000 to 2,500 . Apart from characteristic facial features and congenital 
heart disease, one of the cardinal signs of Noonan syndrome is short stature.

Hypothesizing that hGH (NN-798) may have a growth-promoting effect in children with Noonan syndrome, we investigated the efficacy and safety of NN-798 administered at $0.5 \mathrm{IU} / \mathrm{kg} / \mathrm{wk}$ for 2 years. The present communication reports the results of this study.

\section{Methods}

\section{Subjects}

The subjects were children with Noonan syndrome, who fulfilled the following inclusion criteria: children of either sex with the characteristics of Noonan syndrome (Table 1), chronological age of $5 \mathrm{yr}$ or older, bone age less than $10 \mathrm{yr}$ for boys and less than $8 \mathrm{yr}$ for girls, height at least -2.00 SD below the sex- and age-matched mean height, normal thyroid function (patients on thyroid hormone replacement therapy were acceptable), prior to development of the secondary sexual characteristics (Tanner Stage I), and records available on the increase in height for 1 year before treatment. (See, however, Clinical Characteristics subsection in Results below.)

On the other hand, subjects were not eligible for the study with the following exclusion criteria: females with abnormal sex chromosome, subjects on treatment with sex hormones, anabolic steroids, or corticosteroids, subjects with impaired glucose tolerance or diabetes, subjects with liver disease, renal disease, or serious cardiac dysfunction, subjects with tantrums, subjects with malignant tumors, and subjects with

Table 1. Clinical characteristics of Noonan syndrome

\begin{tabular}{lll}
\hline \multicolumn{1}{c}{ Characteristics } & \multicolumn{1}{c}{ Characteristics } & $\begin{array}{c}\text { Other } \\
\text { malfunctions }\end{array}$ \\
\hline $\begin{array}{l}\text { short stature } \\
\text { high arched palate } \\
\text { epicanthus }\end{array}$ & $\begin{array}{l}\text { low set ear } \\
\text { exophthalmus } \\
\text { webbed neck }\end{array}$ & hearing loss \\
low hairline & short neck & \\
shield like chest & heart anomaly & undescended testis \\
cubitus valgus & micrognathia \\
urinary tract abnormality & intellectual disturbance \\
increased nevi & kinky hair \\
hypertelorism & heart disease \\
antimongolian slant &
\end{tabular}

history of growth hormone therapy. In addition, subjects were rendered unsuitable for the study for other reasons as judged by the attending physician.

Prior to commencement of the study, each attending physician provided the subjects and their guardians with a thorough explanation of the matters listed below and obtained written informed consent to the study: the purpose of the study and method of drug administration, the expected effects and adverse reactions, alternative treatment that may be available for the disease, that the child would not suffer any disadvantage if consent to participate in the study was not given, that the child could withdraw from the study at any time after consent to participation had been given, and other general information pertaining to the protection of the subject's rights. In addition to the informed consent, prior to commencement of the study, the study protocol was approved by the Institutional Review Board of each of the institutes involved in the study.

\section{Study design}

The test drug was recombinant human growth hormone (NN-798; Norditropin $\left.{ }^{\circledR}\right)$. This is a lyophilized preparation containing $12 \mathrm{IU}$ of recombinant somatropin in each vial. The drug was dissolved in $3 \mathrm{~mL}$ of the supplied diluent $(0.25 \mathrm{w} / \mathrm{v} \%$ metacresol), and used within 2 weeks of reconstitution. The drug was stored at $5^{\circ} \mathrm{C}$ with protection from light both before and after reconstitution.

The test drug hGH was administered by subcutaneous injection before bedtime, 7 times per week (total weekly dose: $0.5 \mathrm{IU} / \mathrm{kg}$ ).

The following observations and tests were conducted. Characteristics of Noonan syndrome were examined prior to commencement. Growth hormone stimulation test and urinary GH were performed before commencement. Height, weight, physical changes (including development of secondary sexual characteristics) were observed monthly from commencement to $3 \mathrm{rd}$ month and quarterly from the $3 \mathrm{rd}$ month onwards. Also, concomitant medication and records of compliance with treatment were observed at the same intervals. X-ray films of the left carpal bones were taken for evaluation of bone age (half-yearly from commencement). Hematology tests were performed monthly from commencement to 3rd month and quarterly from the 3 rd month onwards. Clinical chemistry 
tests and urinalysis were performed quarterly from commencement. IGF-1 (insulin-like growth factor) (extraction method), anti-hGH antibodies, $\mathrm{T}_{3}, \mathrm{~T}_{4}, \mathrm{FT}_{4}$, $\mathrm{TSH}$, estradiol (females), and testosterone (males) were analyzed according to standard procedures. The first two items were analyzed by SRL Co., Ltd.

OGTT (oral glucose tolerance test) was measured annually from the commencement. Measurements were performed of blood glucose, IRI (immunoreactive insulin), CPR (C-peptide immunoreactivity), and urinary glucose (urinary glucose at 30 and 90 minutes only) before, and 30,60,90,120, and 180 minutes after oral loading with $1.75 \mathrm{~g} / \mathrm{kg}$ of glucose (max. $75 \mathrm{~g}$ ).

The study began in January 1993 and ended in March 1996.

\section{Statistical analysis and evaluation}

For changes in height velocity, height SD score, and laboratory values, differences from pretreatment values were analyzed by the Wilcoxon one-sample test. Significance was set at $\mathrm{p}<0.05$.

When adverse events occurred, the following information was recorded in the Case Report Form: symptoms, date of onset; date of resolution, severity, (evaluated as 1. mild, 2. moderate, or 3. severe), interventions (if any), causal relationship to the study drug, and course.

On the basis of the adverse events, changes in laboratory data, and other findings made throughout the treatment period, problems with safety were evaluated by the attending physician as either 1) absent or 2) present. For subjects receiving hGH for at least 12 months, treatment was evaluated as effective when the height velocity for the 12-month period was at least $1 \mathrm{~cm} / \mathrm{yr}$ greater than the height velocity $(\mathrm{cm} / \mathrm{yr})$ recorded for the preceding year. Taking into consideration the safety and the increase in stature during the treatment period, the usefulness was evaluated by the attending physician using the following scale: 1 ; useful, 2; neutral, or 3; not useful.

\section{Results}

\section{Disposition of patients}

Fifteen patients ( 8 males and 7 females) diagnosed as having Noonan syndrome on the basis of their physical characteristics were enrolled in the study. Of these, 1 patient (female) had secondary sexual characteristics (Tanner Stage II) and also failed to satisfy the inclusion criterion for bone age (bone age of 11.10), and was therefore excluded from the analysis of efficacy. However, this patient was included for the safety evaluation since she was included in the GH treatment. As a result, 14 patients ( 8 males and 6 females) were evaluated for efficacy after 12 months of treatment. The efficacy was also evaluated after 24 months of treatment for a total of 11 patients, comprising 7 males and 4 females. Laboratory tests, OGTT, and the overall safety data were analyzed for all 15 patients.

\section{Clinical characteristics}

The baseline clinical characteristics of the subjects are shown in Tables 2.1 and 2.2. The chronological age was $7.5 \pm 2.5 \mathrm{yr}$, bone age was $5.8 \pm 2.1 \mathrm{yr}$, height SD score was $-2.8 \pm 0.7$, and pretreatment height velocity was $4.8 \pm 1.0 \mathrm{~cm}$. Birth weight was $3139 \pm$ $874 \mathrm{~g}$ and the gestational age at birth was $39.1 \pm 2.3 \mathrm{wk}$. Paternal height was $170.2 \pm 4.6 \mathrm{~cm}$ and maternal height was $158.1 \pm 3.5 \mathrm{~cm}$. One of the 14 patients had a family history of malformation. Two of the 14 patients exhibited GH deficiency (both females).

As is evident from Table 1, some patients did not satisfy the inclusion criteria. The chronological age of two patients was under $5 \mathrm{yr}$ ( $4.8 \mathrm{yr}$ for case 04001 and $4.5 \mathrm{yr}$ for case 04003 ), and the height SD score of two patients was above -2.0 (-1.9SDS for case 01003 and $-1.6 \mathrm{SDS}$ for case 10001). Although these patients had failed to satisfy the inclusion criteria at the start of the study, they all exhibited typical symptoms of Noonan syndrome. Since the occurrence of Noonan syndrome is rare, these four patients, namely the two patients with the chronological age under $5 \mathrm{yr}$ and the two patients with the height SDS above -2.0, were included in the study by the judgment of the principal investigator.

\section{Growth characteristics}

The height velocity changes are shown in Fig. 1 . The velocity was $4.8 \pm 1.0 \mathrm{~cm} / \mathrm{yr}(\mathrm{n}=14), 7.0 \pm 1.2$ $\mathrm{cm} / \mathrm{yr}(\mathrm{n}=14)$, and $5.5 \pm 0.6 \mathrm{~cm} / \mathrm{yr}(\mathrm{n}=11)$, in the year prior to treatment, $0-12$ months after commencing treatment, and 12-24 months after commencing treatment, respectively. The height velocity in the first 
Table 2.1. Demographic data for patients (1)

\begin{tabular}{|c|c|c|}
\hline Items & Total number of patients & 14 \\
\hline \multirow{2}{*}{ Sex } & M & 8 \\
\hline & $\mathrm{F}$ & 6 \\
\hline \multirow{3}{*}{ Age } & $4 \sim<7$ & 6 \\
\hline & $7 \sim<9$ & 3 \\
\hline & $\geq 9$ & 5 \\
\hline \multirow{3}{*}{ Admission status } & Inpatient $(\mathrm{A})$ & 2 \\
\hline & Outpatient (B) & 12 \\
\hline & $(\mathrm{A})+(\mathrm{B})$ & 14 \\
\hline \multirow{4}{*}{$\begin{array}{l}\text { Degree of growth retardation: } \\
\text { Height SD score before } \\
\text { treatment with hGH }\end{array}$} & $\geq-2.00$ & 2 \\
\hline & $\sim-3.00$ & 7 \\
\hline & $\sim-4.00$ & 4 \\
\hline & $\sim-5.00$ & 1 \\
\hline \multirow{2}{*}{ Complications } & Absent & 5 \\
\hline & Present & 9 \\
\hline \multirow{2}{*}{ Concomitant medications } & Not administered & 13 \\
\hline & Administered & 1 \\
\hline \multirow{2}{*}{ Secondary sex characteristics } & Absent & 14 \\
\hline & Present & 0 \\
\hline \multirow{2}{*}{ Abnormalities at birth } & Absent & 11 \\
\hline & Present & 3 \\
\hline \multirow{2}{*}{ Family history (parents) } & Non-contributory & 13 \\
\hline & Contributory & 1 \\
\hline \multirow{2}{*}{ GH secretion } & non-GHD ${ }^{\text {a) }}$ & 12 \\
\hline & $\mathrm{GHD}^{\mathrm{a})}$ & 2 \\
\hline \multirow{3}{*}{$\begin{array}{l}\text { GH secretion stimulation test } \\
\text { Mean peak value }(\mathrm{ng} / \mathrm{ml})\end{array}$} & $0 \sim 10$ & 2 \\
\hline & $10.1 \sim 20$ & 3 \\
\hline & $20.1 \sim$ & 9 \\
\hline
\end{tabular}

a) GHD: Growth Hormone Deficiency

year of treatment was significantly greater $(\mathrm{P}=$ $0.0001, \mathrm{n}=14$ ) than in the year prior to commencing treatment, but there was no significant difference in the second year of treatment $(\mathrm{P}=0.1230, \mathrm{n}=11)$, as seen in Fig. 1. The height SD scores at commencement of treatment and at 12 and 24 months after commencing treatment are shown in Fig. 2. The scores were $-2.8 \pm 0.7(n=14),-2.4 \pm 0.7(n=14)$, and $-2.2 \pm$ $0.5(\mathrm{n}=11)$, respectively. The scores were significantly different from the pretreatment values after 12 $(\mathrm{P}=0.0002, \mathrm{n}=14)$ and 24 months $\quad(\mathrm{P}=0.0039$, $\mathrm{n}=11$ ), see Fig. 1. For the 12 patients for whom bone age could be evaluated at the commencement of
Table 2.2. Demographic data for patients (2)

\begin{tabular}{|c|c|c|}
\hline \multirow[t]{3}{*}{ No. of Patients } & M & 8 \\
\hline & $\mathrm{F}$ & 6 \\
\hline & Total & 14 \\
\hline \multicolumn{2}{|c|}{ Chronological age (y) } & $\begin{array}{c}7.5 \pm 2.5 \\
(4.5 \sim 12.5)\end{array}$ \\
\hline \multicolumn{2}{|c|}{ Bone age (y) TW2 } & $\begin{array}{c}5.8 \pm 2.1 \\
(2.1 \sim 9.6)\end{array}$ \\
\hline \multicolumn{2}{|c|}{ Height (cm) } & $\begin{array}{c}107.6 \pm 12.3 \\
(90.9 \sim 129.7)\end{array}$ \\
\hline \multicolumn{2}{|c|}{ Body weight (kg) } & $\begin{array}{c}18.5 \pm 4.9 \\
(9.4 \sim 26.8)\end{array}$ \\
\hline \multicolumn{2}{|c|}{ Height SD score } & $\begin{array}{c}-2.8 \pm 0.7 \\
(-4.1 \sim-1.6)\end{array}$ \\
\hline \multicolumn{2}{|c|}{ Malformation score } & $\begin{array}{l}15.3 \pm 5.2 \\
(6 \sim 24)\end{array}$ \\
\hline \multicolumn{2}{|c|}{$\begin{array}{l}\text { Height velocity before treatment } \\
(\mathrm{cm} / \mathrm{y})\end{array}$} & $\begin{array}{c}4.8 \pm 1.0 \\
(2.8 \sim 6.6)\end{array}$ \\
\hline \multicolumn{2}{|c|}{ Birth body weight (g) } & $\begin{array}{c}3139 \pm 874 \\
(850 \sim 4450)\end{array}$ \\
\hline \multicolumn{2}{|c|}{ Gestational age (w) } & $\begin{array}{l}39.1 \pm 2.3 \\
(35 \sim 42)\end{array}$ \\
\hline \multicolumn{2}{|c|}{ Father's height $(\mathrm{cm})$} & $\begin{array}{c}170.2 \pm 4.6 \\
(163.0 \sim 177.0)\end{array}$ \\
\hline \multicolumn{2}{|c|}{ Mother's height $(\mathrm{cm})$} & $\begin{array}{c}158.1 \pm 3.5 \\
(152.0 \sim 163.0)\end{array}$ \\
\hline
\end{tabular}

The numbers in the right column indicate mean \pm standard deviation (top), and the range of the values (minimum $\sim$ maximum) (bottom).

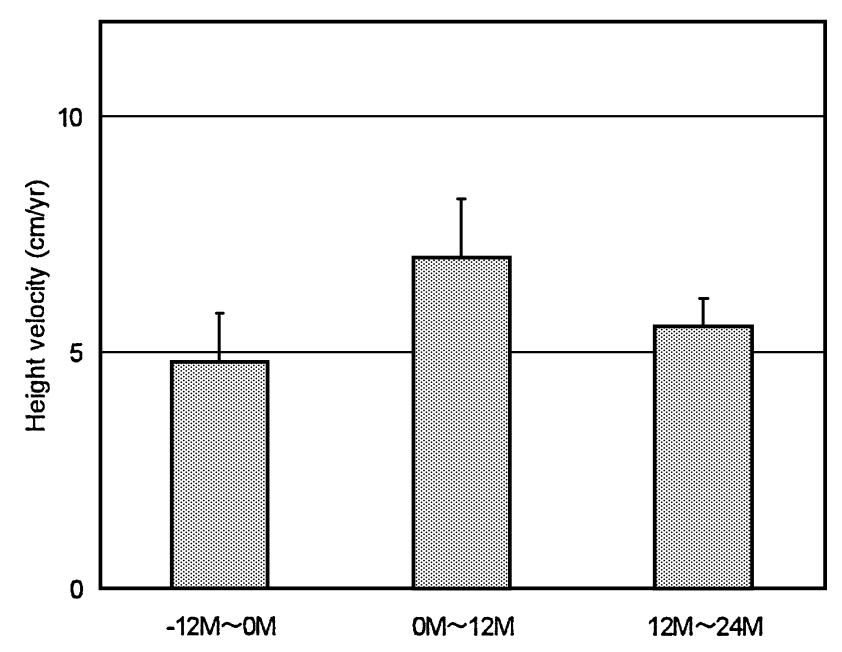

Fig. 1. Changes in height velocity 


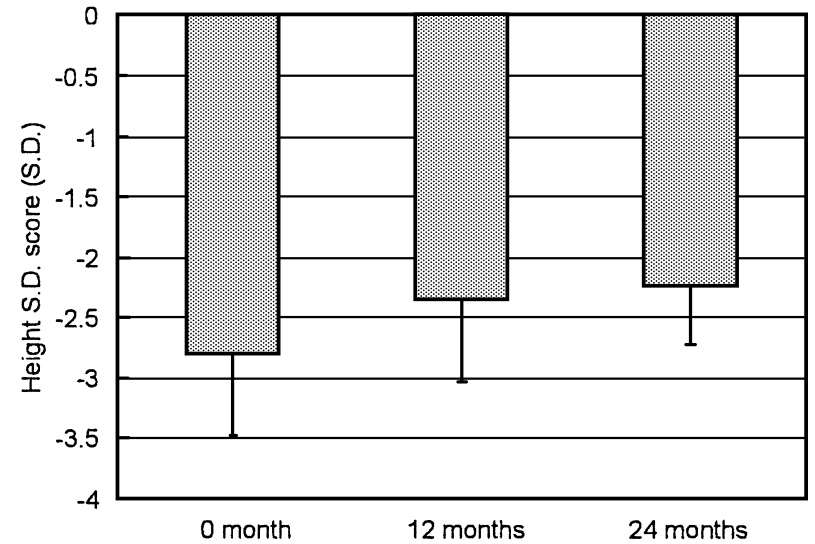

Fig. 2. Changes in height SD scores

treatment and after 12 months of treatment, bone age advanced by $1.1 \pm 0.5 \mathrm{yr}$ in this period.

\section{Individual responses}

To elucidate the general tendency of growth characteristics, responses of individual patients are described in some detail. Specifically, the responses of 2 cases with GH deficiency, 9 cases with severe complications, 3 cases with abnormalities at birth, 1 case with low birth weight, and 1 case of hGH antibody value exceeding 10 are illustrated in Fig. 3. Details of specific conditions are listed in Table 3. Note that the conditions of most of the listed cases are overlapped. Comparison between the cases with and without endogenous GH level showed that there was no relationship between the GH secretion and the height velocity.

\section{Laboratory data}

There was a significant increase in ALP, from $293.0 \pm 124.7 \mathrm{IU} / \mathrm{L}$ at baseline to $442.2 \pm 206.5 \mathrm{IU} / \mathrm{L}$ after 12 months of treatment, while IGF-1 rose from $106.0 \pm 66.5 \mathrm{ng} / \mathrm{mL}$ at baseline to $167.2 \pm 104.4 \mathrm{ng} / \mathrm{mL}$ after 12 months. No significant changes were observed for any other laboratory parameter. A transient 10 -fold rise in the anti-hGH antibody titer was observed in 1 case. No abnormalities in protein, glucose, or urinary sediment were detected by urinalysis during the treatment period.

With respect to the glucose tolerance, there were no significant increases in $\mathrm{HbA}_{1}$ or $\mathrm{HbA}_{1 \mathrm{C}}$ during the treatment period. There were no significant changes in

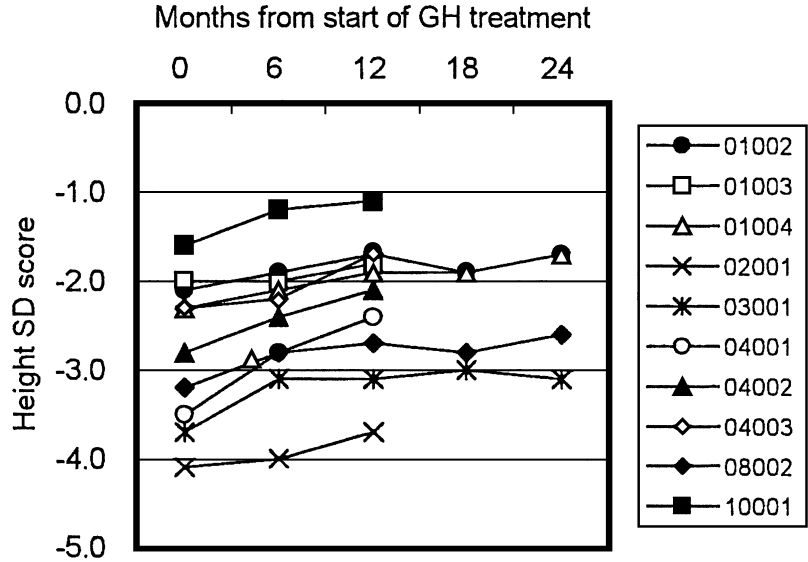

Fig. 3. Changes in height SD scores of individual patients listed in Table 3

Table 3. Characteristics of individual cases

\begin{tabular}{lcc}
\hline \multicolumn{1}{c}{ Characteristics } & ${\text { Case } \mathrm{No}^{\text {a) }}}$ & Description \\
\hline GHD & 04002 & \\
& 04003 & \\
\hline Severe complications & 01002 & ASD $^{\text {b) }}$ \\
& 01003 & ASD + PS $^{\text {c }}$ \\
& 01004 & VSD \\
& 02001 & HOC) \\
& 03001 & PS \\
& 04001 & PS \\
& 04002 & PS \\
& 08002 & PS \\
& 10001 & von Recklinghausen disease \\
\hline Abnormalities at birth & 01004 & Hysterotomy \\
& 03001 & 2nd child at multiple birth \\
& 04003 & Birth asphyxia \\
\hline Low birth weight & 03001 & 850 g at birth \\
& & (gestational age of 35 wk) \\
& & Height at birth unknown \\
\hline hGH antibody $>10$ & 10001 & \\
\hline
\end{tabular}

a) Note that the case number overlaps in some characteristics. Sixteen cases of a total of 10 patients are listed in the table.

b) aortic septal defect, ${ }^{\text {c) }}$ pulmonary stenosis, ${ }^{\text {d) }}$ ventricular septal defect, ${ }^{\text {e) }}$ hypertrophic obstructive cardiomyopathy

blood glucose, IRI, or CPR after 12 months of treatment. When blood glucose levels were scored by the method of Hibi et al. [1], the results were $0.2 \pm 0.4$ (mean $\pm \mathrm{SD}$ ) at baseline and $1.2 \pm 1.2$ after 12 months of treatment. Blood glucose changed from normal to borderline in 5 patients and from borderline to normal in 1 patient. 


\section{Evaluations}

1) Adverse event. Cranial MRI detected an abnormality in 1 of 15 patients during the treatment period. The diagnosis was moderate cerebellar hematoma. No intervention was required, but administration of hGH was discontinued. The patient also had von Recklinghausen disease, and neoplasms are known to be associated with this condition. The causal relationship to hGH therapy was concluded to be unknown.

2) Overall safety rating. The overall safety ratings were assigned by the attending physicians on the basis of adverse events, changes in laboratory values and other findings. Evaluation problems with safety arose for $1(6.7 \%)$ of the 15 patients, who is the patient with the cerebellar hematoma. There was one patient who continued the GH treatment into the second year but failed to visit the relevant hospital soon afterward. There were two other patients in whom the safety evaluation was not possible, namely the girl who had secondary sexual characteristics, and one patient who discontinued the GH treatment at the request of the patient and the patient's guardian (see Usefulness for this case). Thus, 4 patients out of 15 were not available for the overall safety evaluation at the end of 2nd year of treatment.

3) Efficacy. Efficacy was defined as a height velocity for the 12-month administration period of at least $1 \mathrm{~cm} / \mathrm{yr}$ above the height velocity $(\mathrm{cm} / \mathrm{yr})$ recorded for the preceding year. The results of efficacy evaluation are shown in Table 3. The treatment was evaluated as being effective in $11(78.6 \%)$ of 14 cases. Using the conventional definition of effective therapy, which is a height velocity for the 12-month administration period at least $2 \mathrm{~cm} / \mathrm{yr}$ above the height velocity $(\mathrm{cm} / \mathrm{yr})$ for the preceding year, the treatment was evaluated as effective in $6(42.9 \%)$ of 14 cases. Since it is generally known that the height velocity was lower in the second year of GH administration than in the first year, the efficacy evaluation was described only for the first year.

4) Usefulness. From the results for the 12-month period after commencing treatment, and taking into consideration safety and increase in height throughout the treatment period, the assessments of usefulness made by the attending physicians are shown in Table 4. The treatment was evaluated as useful in 12 of 14 cases $(85.7 \%)$, and as neutral in 2 cases $(14.3 \%)$. In 1 of these 2 cases, the height velocity in the year before commencing treatment and in the 12 months after commencing treatment was $3.8 \mathrm{~cm} / \mathrm{yr}$ and $5.2 \mathrm{~cm} / \mathrm{yr}$, respectively, and treatment was discontinued at the request of the patient and the patient's guardian. In the second of these two cases an adverse event occurred as described above. Because of the discontinued case 12 months after commencing treatment and because of the above-mentioned point of efficacy evaluation, the usefulness evaluation was described only for the results obtained in the first 12 months after commencing treatment.

Table 4. Overall safety, efficacy and usefulness ratings

\begin{tabular}{|c|c|c|c|}
\hline \multicolumn{4}{|c|}{ Safety } \\
\hline Treatment period & Safety problems absent & Safety problems present & Total \\
\hline 1 st year of treatment & $\begin{array}{l}14 \text { cases } \\
(93.3 \%)\end{array}$ & $\begin{array}{l}1 \text { case } \\
(6.7 \%)\end{array}$ & $\begin{array}{c}15 \text { cases } \\
(100.0 \%)\end{array}$ \\
\hline 2nd year of treatment & $\begin{array}{c}11 \text { cases } \\
(100.0 \%)\end{array}$ & $\begin{array}{l}0 \text { case } \\
(0.0 \%)\end{array}$ & $\begin{array}{c}11 \text { cases } \\
(100.0 \%)\end{array}$ \\
\hline \multicolumn{4}{|c|}{ Efficacy } \\
\hline Treatment period & Height velocity $\geq 1 \mathrm{~cm}$ & Height velocity $<1 \mathrm{~cm}$ & Total \\
\hline 1 st year of treatment & $\begin{array}{l}11 \text { cases } \\
(78.6 \%)\end{array}$ & $\begin{array}{c}3 \text { cases } \\
(21.4 \%)\end{array}$ & $\begin{array}{c}14 \text { cases } \\
(100.0 \%)\end{array}$ \\
\hline \multicolumn{4}{|c|}{ Usefulness } \\
\hline Treatment period & Useful & Neutral & Total \\
\hline 1st year of treatment & $\begin{array}{l}12 \text { cases } \\
(85.7 \%)\end{array}$ & $\begin{array}{c}2 \text { cases } \\
(14.3 \%)\end{array}$ & $\begin{array}{c}14 \text { cases } \\
(100.0 \%)\end{array}$ \\
\hline
\end{tabular}




\section{Discussion}

While it has phenotypic similarities to Turner syndrome, Noonan syndrome is characterized by a normal karyotype and the syndrome also affects males. In a study performed in 1985 by Hayakawa et al., the predominant features of Noonan syndrome were short stature, cubitus valgus, hypertelorism, antimongoloid optic fissure, low auricles, exophthalmos, webbed neck, short neck, low hairline, and cardiomyopathy [2].

With regard to short stature, a German report on Noonan syndrome indicated that the mean height for males up to $12 \mathrm{yr}$ and females up to $10 \mathrm{yr}$ was in the 3rd percentile. Following a subsequent growth spurt and delayed development of secondary sexual characteristics, however, the final height was within the normal range (above -2 SD) [3].

Despite this, given the psychological burden associated with short stature during the impressionable childhood years and the possibility that social life might be impaired, providing therapy for short stature is an important challenge. Treatment with hGH may benefit patients with impaired growth. We therefore administered hGH at $0.5 \mathrm{IU} / \mathrm{kg} / \mathrm{wk}$ to 15 patients ( 8 males and 7 females) with Noonan syndrome. We observed a growth-promoting effect in 14 patients who underwent 12 months of treatment prior to the development of secondary sexual characteristics. The height velocity in the year before commencing treatment was $4.8 \pm 1.0 \mathrm{~cm} / \mathrm{yr}$, rising to $7.0 \pm 1.2 \mathrm{~cm} / \mathrm{yr}$ after treatment for 12 months. The height SD score prior to treatment was $-2.8 \pm 0.7$, and at 12 and 24 months after commencement of treatment it was $-2.4 \pm 0.7$ and $-2.2 \pm 0.5$, respectively, thus showing a statistically significant improvement. Bone age advanced by $1.1 \pm 0.5 \mathrm{yr}$ in the 12-month period after commencing treatment, corresponding to the increase in chronological age.

Administration of hGH was discontinued in 1 patient during the treatment period, as cranial MRI detected an abnormality. The relationship of this adverse event to hGH therapy was unclear, and the abnormality was suspected to be due to a pre-existing complication. As several malformations are associated with Noonan syndrome, careful attention is warranted during treatment with hGH.

In a study reported by Cotterill et al., 27 children (16 males and 11 females) with Noonan syndrome were treated for 12 months with $\mathrm{hGH}\left(4 \mathrm{IU} / \mathrm{m}^{2} /\right.$ day). The height velocity increased from $4.9 \pm 0.2 \mathrm{~cm} / \mathrm{yr}$ at baseline to $8.9 \pm 0.3 \mathrm{~cm} / \mathrm{yr}$ at $0-6$ months, and $8.1 \pm$ $0.4 \mathrm{~cm} / \mathrm{yr}$ at $6-12$ months [4]. Romano et al. analyzed growth data for 150 children (97 males) with Noonan syndrome who received hGH therapy $(0.31 \mathrm{mg} / \mathrm{kg} / \mathrm{wk}$, or approximately $0.9 \mathrm{IU} / \mathrm{kg} / \mathrm{wk}$ ) over a period of 4 years, and found that the height velocity increased from $4.3 \pm 2.3 \mathrm{~cm} / \mathrm{yr}$ at baseline to $8.0 \pm 2.0 \mathrm{~cm} / \mathrm{yr}$ in the 12-month period after commencing treatment [5].

The dose of the above studies $[4,5]$ was approximately 2.0 times that used in the present study ( $0.5 \mathrm{IU} /$ $\mathrm{kg} / \mathrm{wk}$ ). Since the effect of GH shows a dose-response relationship, it is expected that the effect of $\mathrm{GH}$ in Noonan syndrome also obeys a similar dose dependency. It is therefore suggested that the dose level similar to those used in these studies is required to achieve satisfactory effects of GH treatment.

It is of interest to note that hGH promotes growth to a greater extent in patients with Noonan syndrome than in girls with Turner syndrome, although its effect is not as pronounced as it is in the treatment of growth hormone-deficient short stature. This is still a relatively new field of research and there is a need for further studies into factors such as the final height, bone age, influence on sexual development and adverse events.

\section{Conclusions}

1. We investigated the efficacy and safety of hGH therapy ( $0.5 \mathrm{IU} / \mathrm{kg} / \mathrm{wk}$ for 24 months) in 15 patients (8 males and 7 females) with Noonan syndrome.

2. The height velocity in the year before commencing treatment, $0-12$ months after commencing treatment, and 12-24 months after commencing treatment was $4.8 \pm 1.0 \mathrm{~cm} / \mathrm{yr}, 7.0 \pm 1.2 \mathrm{~cm}$, and $5.5 \pm 0.6 \mathrm{~cm} / \mathrm{yr}$, respectively. Compared with the height velocity in the year prior to treatment, the height velocity was significantly greater in the first year, but not in the second year of treatment.

3. The height SD score at the commencement of treatment, and after 12 and 24 months of treatment, was $-2.8 \pm 0.7,-2.4 \pm 0.7$, and $-2.2 \pm 0.5$, respectively.

4. Bone age advanced by $1.1 \pm 0.5 \mathrm{yr}$ in the 12 -month period after commencing treatment.

5. During the treatment period, cranial MRI detected an abnormality in 1 patient, but the relationship to hGH therapy was unclear.

6. The use of hGH may be beneficial in the treatment of Noonan syndrome. 


\section{References}

1. Hibi I, Isshiki G, Egi S, Kitagawa T, Takada G, Tanae A, Takeda A, Tsuchiya H, Teshirogi T, Matsuura N, Maruyama H, Miki E, Mimura G, Watanabe N, Mano $\mathrm{T}$ (1982) Procedures and standardization of the judgement criteria of the oral glucose tolerance test in children of seven years or older. J Jpn Diab Soc 25: 57-60.

2. Hayakawa F, Tsukidate K, Mori O, Ogawa M, Miwa K, Yazawa T, Nakayama T (1985) Clinical investigation of thirty cases of Turner syndrome and sixteen cases of Noonan syndrome. Jpn J Pediatr 38: 26252631.

3. Ranke MB, Heidemann $\mathrm{P}$, Knupfer $\mathrm{C}$, Endes $\mathrm{H}$, Schmaltz AA, Bierich JR (1988) Noonan syndrome:
Growth and clinical manifestations in 144 cases. Eur $J$ Pediatr 148: 220-227.

4. Cotterill AM, McKenna WJ, Brady AF, Sharland M, Elsawi M, Yamada M, Camacho-Hübner C, Kelnar CJH, Dunger DB, Patton MA, Savage MO (1996) The short-term effects of growth hormone therapy on height velocity and cardiac ventricular wall thickness in children with Noonan's syndrome. J Clin Endocrinol Metab 81: 2291-2297.

5. Romano AA, Blethen SL, Dana K, Noto RA (1996) Growth hormone treatment in Noonan syndrome: The national cooperative growth study experience. $J$ Pediatr 128: S18-21. 